\title{
Valor Nutritivo do Capim-Elefante (Penninsetum purpureum, Schum), do Feno de Alfafa (Medicago sativa, L.) e do Feno de Capim Coast-cross (Cynodon dactylon (L.) Pers.) para Eqüinos ${ }^{1}$
}

\section{Maria Izabel Vieira de Almeida ${ }^{2}$, Walter Motta Ferreira ${ }^{3}$, Fernando Queiroz de Almeida ${ }^{4}$, Carlos Alberto Saint Just ${ }^{4}$, Lúcio Carlos Gonçalves ${ }^{3}$, Adalgisa Souza Carneiro Rezende ${ }^{3}$}

\begin{abstract}
RESUMO - O objetivo deste trabalho foi avaliar o consumo e a digestibilidade aparente dos nutrientes nos alimentos volumosos capimelefante, feno de alfafa e feno de capim coast-cross em eqüinos adultos. Dezoito éguas adultas da raça Mangalarga Marchador foram distribuídas em delineamento experimental inteiramente casualizado, com três tratamentos, que consistiram em dietas contendo os seguintes alimentos volumosos: $\mathrm{T}_{1}$ - capim-elefante, $\mathrm{T}_{2}$ - feno de alfafa e $\mathrm{T}_{3}$ - feno de capim coast-cross. Os animais foram alimentados ad libitum, duas vezes ao dia. O período experimental constituiu de uma fase de oito dias para adaptação às dietas e cinco dias para a coleta total das fezes. Não houve diferenças no consumo diário de matéria seca (MS) das forragens, sendo observados valores médios de 6,27 kg MS, 68,41 $\mathrm{g} \mathrm{MS} / \mathrm{kg}^{0,75}$ ou 1,51\%PV. Os coeficientes médios de digestibilidade aparente do capim-elefante e dos fenos de alfafa e capim coast-cross foram de 43,10; 55,20; e 49,80\% para a MS; 41,60; 53,40; e 47,90\% para a energia bruta; 24,60; 71,20; e 56,10\% para a proteína bruta; e 40,$60 ; 35,50$; e $63,30 \%$ para a fibra em detergente neutro.
\end{abstract}

Palavras-chave: forragens, digestibilidade, energia, proteína, mantença

\section{Nutritive Value of Elephant grass (Penninsetum purpureum, Schum), Alfalfa Hay (Medicago sativa, L.) and Coast-Cross Grass Hay (Cynodon dactylon (L.) Pers.) for Horses}

\begin{abstract}
The objective of this work was to evaluate the intake and apparent digestibility of nutrients of elephant grass forages, alfalfa and coast-cross grass hays in adult horses. Eighteen adult Mangalarga Marchador mares were allotted to a completely randomized design with three treatments that consisted on diets with the following forages: T1 - elephant grass, T2 - alfalfa hay, T3 - coast-cross grass hay. The animals were ad libitum fed twice a day. The experimental period was constituted by a phase of eight days for diet adaptation and a phase of five days for total collection of feces. There were no differences of forage dry matter intake, with average values of 6.27 $\mathrm{kg} \mathrm{DM}, 68.41 \mathrm{~g} \mathrm{DM} / \mathrm{kg}^{0,75}$ or $1.51 \% \mathrm{LW}$. The average coefficients of apparent digestibility of elephant grass and alfalfa and coast-cross grass hays were $43.10,55.20$, and $49.80 \%$ for DM, 4160, 53.40, and $47.90 \%$ for gross energy, $24.60 ; 71.20$ and $56.10 \%$ for crude protein and $40.60,35.50$, and $63.30 \%$ for neutral detergent fiber.
\end{abstract}

Key Words: forages, digestibility, energy, protein, maintenance

\section{Introdução}

O valor nutritivo de uma forragem normalmente refere-se ao conjunto formado pela composição química da forragem, à sua digestibilidade e à natureza dos produtos da digestão (REIS e RODRIGUES, 1993).

A digestibilidade de nutrientes orgânicos nos alimentos é comumente expressa em porcentagem da matéria seca que desaparece no balanço entre alimento ingerido e excreção de fezes (VAN SOEST, 1994). O sistema de avaliação de alimentos normalmente utilizado para eqüinos tem sido o mesmo usado para ruminantes, embora diferenças importantes, no que diz respeito ao processo de digestão, devam ser observadas, por causa da diferença na compartimentalização do trato digestivo, o que se traduz em diferentes digestibilidades dos alimentos (SMOLDERS et al., 1990).

O cavalo é um animal herbívoro, que digere principalmente carboidratos de reserva citoplasmática, proteínas e lipídeos, da mesma forma que os suínos, entretanto a extensa população bacteriana presente no intestino grosso permite ao eqüino a utilização de carboidratos estruturais (MERTENS, 1992). Segundo

\footnotetext{
${ }^{1}$ Parte da Dissertação apresentada à Universidade Federal de Minas Gerais para obtenção do título de Magister Scientiae

2 Zootecnista, Doutorando em Zootecnia. DZO - UFV - 36571-000 - Viçosa, MG. miva@homenet.com.br

3 Professor do DZO - EV- UFMG - 30161-970 - Belo Horizonte, MG.

4 Professor do DPA - IZ - UFRRJ - 23851-970 - Seropédica. RJ.
} 
MARTIN-ROSSET e DULPHY (1987), na espécie eqüina, cerca de 70 a $95 \%$ do conteúdo celular são digeridos no intestino delgado, enquanto os constituintes da parede celular o são no intestino grosso.

As forragens, provavelmente, constituem a categoria de alimentos mais abundante, porém a maior parte de sua matéria orgânica está na forma de polissacarídeos insolúveis e indigestíveis, que se acumulam com o avançar da idade dos vegetais. Em animais ruminantes e não-ruminantes com ceco e cólon funcionais, como o eqüino, o maior conteúdo celular aumenta a digestibilidade do alimento, mas, nos animais com pouco conteúdo celular, a digestibilidade pode ser elevada quando a parede celular for altamente digestível (VAN ES e VAN DER MEER, 1980).

Segundo PAGAN (1996), vários fatores influenciam o consumo e a qualidade das forragens, sendo a espécie forrageira, o estádio de maturidade da planta, a latitude e a presença de substâncias inibitórias no alimento os mais importantes. Considerando que a capacidade estomacal do eqüino é pequena, menos de $10 \%$ do volume total do trato digestivo, os eqüinos não podem ingerir grandes quantidades de alimento fibroso, entretanto, o intestino grosso (ceco e cólon) é muito desenvolvido representando cerca de $60 \%$ do volume do trato digestivo, com funções semelhantes às do rúmen (TISSERAND, 1988).

Os eqüinos alimentados ad libitum com dietas contendo alta proporção de forragem compensam o menor conteúdo energético, consumindo cerca de $26 \%$ mais alimento que animais alimentados com dieta rica em concentrado (CYMBALUK, 1989). Segundo HINTZ (1988), em animais alimentados em níveis três vezes acima das exigências para mantença, o nível de consumo pode influir na digestibilidade dos nutrientes e reduzir a digestibilidade das dietas de 12 a $13 \%$, quando comparadas em animais alimentados em nível de mantença.

O objetivo deste trabalho foi avaliar o consumo e a digestibilidade aparente dos nutrientes nos alimentos volumosos capim-elefante e fenos de alfafa e de capim coast-cross em eqüinos adultos.

\section{Material e Métodos}

O presente trabalho foi conduzido no Setor de Eqüinocultura do Instituto de Zootecnia da Universidade Federal Rural do Rio de Janeiro, Seropédica, RJ, e as análises químicas realizadas no Laboratório de Bromatologia do Instituto de
Zootecnia, UFRRJ, e no Laboratório de Nutrição Animal do Departamento de Zootecnia da Universidade Federal de Viçosa, Viçosa, MG.

Foram utilizados 18 eqüinos da raça Mangalarga Marchador, do sexo feminino, com peso de $414 \pm 43 \mathrm{~kg}$ e idade de 7,5 $\pm 3,0$ anos. No período pré-experimental, os animais foram mantidos em piquetes com pastagens naturais e submetidos a tratamentos contra endoparasitas e ectoparasitas. No período experimental, os animais foram mantidos em baias individuais de alvenaria de aproximadamente $12 \mathrm{~m}^{2}$, com piso e cochos de alvenaria e sem cama, sendo exercitados ao passo, uma vez ao dia, durante 10 minutos.

Foram utilizados três tratamentos, que consistiram em dietas simples com os seguintes alimentos volumosos:

$\mathrm{T}_{1}$ - Capim-elefante (Penninsetum purpureum, Schum, var. Napier);

$\mathrm{T}_{2}$ - Feno de alfafa (Medicago sativa, L.); e

$\mathrm{T}_{3}$ - Feno de capim coast-cross (Cynodon dactylon (L.) Pers.).

O capim elefante foi produzido, pré-murchado e picado no local, tendo sido cortado com aproximadamente 60 dias de idade. Os fenos de alfafa e capim coast-cross foram adquiridos no comércio local e fornecidos aos animais sem qualquer processamento. Além dos alimentos volumosos, forneceu-se suplemento mineral e vitamínico, cerca de $15 \mathrm{~g}$ por animal, adicionado diariamente no cocho sobre os alimentos.

O período experimental compreendeu de oito dias para adaptação às dietas e cinco dias para a coleta total das fezes. Os animais foram alimentados $a d$ libitum sendo os alimentos fornecidos duas vezes ao dia, às 8 e 16 h, e as sobras recolhidas nos cochos diariamente antes do fornecimento da dieta matutina. No início do período experimental, foram distribuídos seis animais por tratamento, contudo, durante a fase de adaptação, foram retiradas duas éguas do $\mathrm{T}_{1} \mathrm{e}$ uma égua do $T_{2}$, por apresentarem sintomatologia de cólica por impactação. Além disso, os resultados de digestibilidade obtidos para uma das éguas do $T_{2}$ foram eliminados, por terem sido bastante inferiores aos dos demais animais do mesmo tratamento.

Durante o período de coleta os alimentos fornecidos e as sobras foram pesados individualmente, obtendo-se, assim, o consumo diário de cada animal. As fezes foram recolhidas imediatamente após a defecação, colocadas em sacos plásticos individuais e pesadas a cada seis horas, às $6 ; 12 ; 18$; e 24 h. Após a pesagem, o material foi homogeneizado, retiradas alíquotas diárias de $200 \mathrm{~g}$ e armazenadas sob refrigeração a $-5^{\circ} \mathrm{C}$. Posteriormente, estas alíquotas foram 
descongeladas, misturadas, homogeneizadas e submetidas à pré-secagem em estufa de ventilação forçada, a $55^{\circ} \mathrm{C}$, por 72 horas; em seguida, foram moídas em moinho tipo Thomas, com peneira de $1 \mathrm{~mm}$.

Amostras de alimentos e sobras coletadas foram armazenadas sob refrigeração a $-5^{\circ} \mathrm{C}$. As amostras de capim elefante e sobras foram submetidas ao mesmo procedimento de pré-secagem e moagem das amostras de fezes, enquanto as amostras dos fenos de alfafa e coastcross foram moídas, sem sofrer pré-secagem.

As amostras de alimentos, sobras e fezes foram analisadas para a determinação dos teores de matéria seca (MS), proteína bruta (PB), extrato etéreo (EE), energia bruta (EB), matéria mineral e fibra bruta (FB), segundo metodologia descrita por SILVA (1990). Os componentes da parede celular, fibra em detergente neutro (FDN), fibra em detergente ácido (FDA), lignina (LIG), celulose (CEL) e hemicelulose (HEM) foram determinados segundo metodologia descrita por VAN SOEST (1967) e VAN SOEST et al. (1991).

Os coeficientes de digestibilidade aparente dos nutrientes foram calculados a partir dos resultados das análises laboratoriais, aplicados à seguinte equação:

$$
\text { Digestibilidade }(\%)=\frac{\begin{array}{l}
\text { MS cons. } \times(\% \text { Nutr. })- \\
\text { MS fecal } \times(\% \text { Nutr. })
\end{array}}{\text { MS cons. } \times(\% \text { Nutr. })} \times 100
$$

Os nutrientes digestíveis dos alimentos foram calculados multiplicando-se os teores dos nutrientes na composiçãode cada alimento pelo coeficiente de digestibilidade dos mesmos.

O delineamento experimental utilizado foi o inteiramente casualizado, com três tratamentos (alimentos) e seis repetições para o tratamento $T_{3}$ e quatro repetições para os tratamentos $\mathrm{T}_{1}$ e $\mathrm{T}_{2}$, adotando-se o seguinte modelo:

em que

$$
\mathrm{Y}_{\mathrm{ij}}=\mathrm{m}+\mathrm{A}_{\mathrm{i}}+\mathrm{e}_{\mathrm{ij}}
$$

$\mathrm{Y}_{\mathrm{ij}}=$ valor observado das variáveis estudadas, relativo a cada animal $\mathrm{j}$, recebendo o alimento i ;

$\mathrm{m}=$ média geral da característica;

$\mathrm{A}_{\mathrm{i}}=$ efeito do alimento $\mathrm{i}$, sendo $\mathrm{i}=1,2$ e 3 e $\mathrm{i}_{1}=$ capim-elefante, $\mathrm{i}_{2}=$ feno de alfafa e $\mathrm{i}_{3}=$ feno de capim coast-cross; e

$\mathrm{e}_{\mathrm{ij}}=$ erro aleatório associado a cada observação.

Os resultados foram analisados por meio de análise de variância e as médias foram comparadas pelo teste Student-Newman-Keuls, adotando-se o nível de $5 \%$ de probabilidade, utilizando o programa SAEG (UFV, 1997).

\section{Resultados e Discussão}

A composição química dos alimentos volumosos utilizados no presente trabalho encontra-se na Tabela 1. A composição química do capim-elefante foi similar aos valores obtidos na literatura (FERREIRA et al., 1995; FURTADO et al., 1995; OLIVEIRA, 1995; e PEREIRA e QUEIROZ, 1997). A composição química do feno de alfafa e do feno de capim coastcross, de modo geral, está de acordo com a composição média destes alimentos citada no NRC (1989).

Os consumos médios diários de matéria seca, expressos em $\mathrm{kg} / \mathrm{dia}$, percentual do peso vivo (\%PV) e gramas de MS, em função do peso metabólico ( $\mathrm{g}$ $\mathrm{MS} / \mathrm{kg}^{0,75}$ ), encontram-se na Tabela 2. Não foram constatadas diferenças significativas no consumo diário de MS, quando este foi expresso em $\mathrm{kg} \mathrm{MS,} \mathrm{g}$ $\mathrm{MS} / \mathrm{kg}^{0,75}$ ou \%PV. Os resultados médios do consumo diário de MS assemelham-se aos previstos no NRC (1989), para cavalos adultos consumindo dietas exclusivas em forragens $(1,5 \% \mathrm{PV})$, porém o consumo médio do feno de capim coast-cross foi 7,3\% inferior ao recomendado. Segundo MEYER (1995), a capacidade de consumo nos eqüinos adultos em mantença varia em função das raças, $2,5 \%$ do peso vivo para raças de pequeno porte, $2,0 \%$ para raças de porte médio e 1,5 a 2,0\% para raças de grande porte.

O consumo voluntário de matéria seca do capim elefante foi de $1,55 \% \mathrm{PV}$ ou $69,45 \mathrm{~g} \mathrm{MS} / \mathrm{kg}^{0,75}$, inferior ao consumo observado por FERREIRA et al. (1995), de $2,30 \% \mathrm{PV}$ ou $100,64 \mathrm{~g} \mathrm{MS} / \mathrm{kg}^{0,75}$, para potros em crescimento da raça Campolina. Consumos mais elevados de MS em dietas exclusivas de capim elefante, para potros em crescimento mestiços das raças Bretão e Campolina, foram observados por FURTADO et al. (1995), de 2,70\% PV; OLIVEIRA (1995), de 1,90\% PV ou 73,5 g MS/kg0,75; e PEREIRA e QUEIROZ (1997), de $2,60 \% \mathrm{PV}$ ou $92,40 \mathrm{~g} \mathrm{MS} / \mathrm{kg}^{0,75}$.

O consumo voluntário de matéria seca do feno de alfafa foi de 1,66\% PV ou 75,55 $\mathrm{g} \mathrm{MS} / \mathrm{kg}^{0,75}$. CUDDEFORD et al. (1995) observaram valores inferiores no consumo voluntário de feno de alfafa, de $1,04 \% \mathrm{PV}$ ou $49,7 \mathrm{~g} \mathrm{MS} / \mathrm{kg}^{0,75}$, em eqüinos adultos da raça Puro Sangue Inglês, e de $0,96 \% \mathrm{PV}$ ou $45,0 \mathrm{~g}$ $\mathrm{MS} / \mathrm{kg}^{0,75}$, em pôneis adultos da raça Highland, alimentados em nível de mantença. Por outro lado, consumo voluntário mais elevado em dietas exclusivas de feno de alfafa foi observado por TOSI et al. (1982), de 3,02\% PV ou 129,8 g MS/ $\mathrm{kg}^{0,75}$, para potros em crescimento da raça Brasileiro de Hipismo.

O consumo voluntário de matéria seca do feno de 
ALMEIDA et al.

Tabela 1 - Composição química do capim-elefante, feno de alfafa e feno de capim coast-cross (\%MS) Table 1 - Chemical composition of elephant grass, alfalfa hay and coast-cross grass hay (\% DM)

\begin{tabular}{lccc}
\hline & $\begin{array}{c}\text { Capim-elefante } \\
\text { Elephant grass }\end{array}$ & $\begin{array}{c}\text { Feno de alfafa } \\
\text { Alfalfa hay }\end{array}$ & $\begin{array}{c}\text { Feno de capim coast-cross } \\
\text { Coast-cross grass hay }\end{array}$ \\
\hline $\begin{array}{l}\text { Matéria seca (\%) } \\
\text { Dry matter }\end{array}$ & 26,02 & 85,71 & 85,48 \\
$\begin{array}{l}\text { Matéria orgânica (\%) } \\
\text { Organic matter }\end{array}$ & 93,43 & 90,60 & 95,30 \\
$\begin{array}{l}\text { Energia bruta (Mcal/kg MS) } \\
\text { Gross energy }\end{array}$ & 4,278 & 4,360 & 4,343 \\
$\begin{array}{l}\text { Proteína bruta (\%) } \\
\text { Crude protein }\end{array}$ & 3,53 & 19,43 & 6,27 \\
$\begin{array}{l}\text { Extrato etéreo (\%) } \\
\text { Ether extract }\end{array}$ & 3,14 & 4,06 & 2,92 \\
$\begin{array}{l}\text { Fibra bruta (\%) } \\
\text { Crude fiber }\end{array}$ & 40,70 & 30,23 & 37,21 \\
$\begin{array}{l}\text { Fibra em detergente neutro (\%) } \\
\text { Neutral detergent fiber }\end{array}$ & 87,06 & 58,69 & 88,55 \\
$\begin{array}{l}\text { Fibra em detergente ácido (\%) } \\
\text { Acid detergentfiber }\end{array}$ Celulose (\%) & 47,12 & 36,54 & 45,97 \\
$\begin{array}{l}\text { Cellulose } \\
\text { Hemicelulose (\%) }\end{array}$ & 40,74 & 26,93 & 39,02 \\
Hemicellulose & & 22,15 & 42,50 \\
$\begin{array}{l}\text { Lignina (\%) } \\
\text { Lignin }\end{array}$ & 39,94 & 9,61 & 6,95 \\
\hline
\end{tabular}

Tabela 2 - Consumo médio diário de matéria seca de éguas da raça Mangalarga Marchador Table 2 - Average daily intake of dry matter of Mangalarga Marchador mares

\begin{tabular}{lccc}
\multirow{2}{*}{$\begin{array}{l}\text { Diet } \\
\text { Dieta }\end{array}$} & \multicolumn{3}{c}{$\begin{array}{c}\text { Consumo de matéria seca } \\
\text { Dry matter intake }\end{array}$} \\
\cline { 2 - 4 } & $\begin{array}{r}\mathrm{kg} \mathrm{MS} \\
\mathrm{kg} \mathrm{DM}\end{array}$ & $\begin{array}{c}\mathrm{g} \mathrm{MS} / \mathrm{kg}^{0}, 75 \\
\mathrm{~g} \mathrm{DM} / \mathrm{kg}^{.75}\end{array}$ & $\% \mathrm{PV}$ \\
\hline $\begin{array}{l}\text { Capim-elefante } \\
\text { Elefant grass }\end{array}$ & 6,23 & 69,45 & 1,55 \\
$\begin{array}{l}\text { Feno de alfafa } \\
\text { Alfafa hay }\end{array}$ & 7,03 & 75,55 & 1,66 \\
$\begin{array}{l}\text { Feno de capim coast-cross } \\
\text { Coast-cross grass hay }\end{array}$ & 5,79 & 62,96 & 1,39 \\
$\begin{array}{l}\text { Média } \\
\text { Mean }\end{array}$ & 6,27 & 68,41 & 1,51 \\
CV $(\%)$ & 14,4 & 12,1 & 12,4 \\
\hline
\end{tabular}

capim coast-cross foi de $1,39 \% \mathrm{PV}$ ou $62,96 \mathrm{~g} \mathrm{MS} /$ $\mathrm{kg}^{0,75}$, inferior ao consumo observado em eqüinos adultos em mantença por LIEB et al. (1993), de 2,77\% PV, e DUGAN et al. (1993), de 2,47\% PV. TOSI et al. (1982) observaram que o consumo voluntário de MS em dietas exclusivas de feno de capim coast-cross foi de $1,85 \% \mathrm{PV}$ ou $83,2 \mathrm{~g} \mathrm{MS} / \mathrm{kg}^{0,75}$, para potros em crescimento da raça Brasileiro de Hipismo, enquanto AIKEN et al. (1989) observaram que o consumo de MS do feno de capim coast-cross foi superior em potros em crescimento, de $2,50 \% \mathrm{PV}$, quando comparados com eqüinos adultos em mantença, de 2,0\% PV.
Vários autores têm enfocado o controle do consumo de alimentos pelos eqüinos de forma diferenciada. Segundo RALSTON (1984), o controle da ingestão de alimentos na espécie eqüina ocorre pela interferência de fatores pré-gástricos, gastrointestinais e metabólicos, enquanto HOUPT (1990) descreve os controles clássicos de controle de consumo: termostático, lipostático e glucostático como sendo os mecanismos de controle envolvidos. Entretanto, MEYER (1995) diferencia mecanismos de longo e curto prazo na regulação da ingestão de alimentos, sendo a manutenção do peso vivo relacionada com os mecanismos de longo prazo, ao passo que os de curto 
prazo determinariam o início e o término de cada refeição e ambos os mecanismos estariam integrados pelo centro de ingestão de alimentos no Sistema Nervoso Central.

Segundo CYMBALUK (1989), a quantidade de alimento ingerida é determinada pela sua densidade energética; sendo esta baixa, o consumo aumenta e vice-versa. ARCHER (1973), contudo, observa que não há correlação do conteúdo em energia bruta de espécies forrageiras e o consumo voluntário pelos eqüinos. Segundo MINSON (1990), é esperado, em bovinos, maior consumo voluntário das leguminosas, quando comparado ao das gramíneas, podendo esta diferença estar relacionada com a menor resistência à quebra das partículas dos alimentos e a menor percentagem de parede celular e da energia requerida na mastigação das leguminosas. No presente experimento, verificou-se que o consumo de matéria seca do feno de alfafa foi $16,6 \%$ superior ao consumo do feno de capim coast-cross, semelhante ao observado por CROZIER et al. (1997) e DULPHY et al. (1997), superior em 16,4 e 13,8\%, respectivamente, para o consumo do feno de alfafa, quando comparado ao consumo dos fenos de gramíneas. O consumo voluntário em matéria seca do capim-elefante no presente experimento foi $8,1 \%$ menor em relação ao feno de alfafa, semelhante ao observado por DULPHY et al. (1997), inferior em $10,2 \%$, para o consumo de forragens verdes, quando comparado ao consumo do feno de alfafa.

DULPHY et al. (1994) correlacionaram o consumo voluntário de MS de forragens, expresso em $\mathrm{g}$ $\mathrm{MS} / \mathrm{kg}^{0,75}$, ao teor de fibra em detergente ácido (FDA) na MS, obtendo a seguinte equação: Consumo $\mathrm{MS}=153-1,46 \mathrm{FDA}\left(\mathrm{r}^{2}=0,52\right)$, que, aplicada aos valores de FDA dos alimentos avaliados, superestima o consumo de MS em 21,2; 31,8 e 36,4\% para o capim-elefante, feno de alfafa e feno de capim coastcross, respectivamente.

Os coeficientes médios de digestibilidade aparente de matéria seca (MS), matéria orgânica (MO), energia bruta $(\mathrm{EB})$, proteína bruta $(\mathrm{PB})$, extrato etéreo (EE), fibra bruta (FB), fibra em detergente neutro (FDN), fibra em detergente ácido (FDA), celulose (CEL), hemicelulose (HEM) e lignina (LIG) dos alimentos avaliados encontram-se na Tabela 3.

O coeficiente de digestibilidade aparente da matéria seca (CDMS) do capim-elefante no presente experimento foi de 43,10\%, valor próximo ao obtido por PEREIRA e QUEIROZ (1997), de 47,53\%, sendo o capim-elefante cortado aos 70 dias de idade. Outros autores observaram resultados inferiores no CDMS, como ARAÚJO et al. (1996), de 34,42\%; FERREIRA et al. (1995), de 29,27\%; FURTADO et al. (1995), de $33,60 \%$; e OLIVEIRA et al. (1997), de 23,10\%.

O coeficiente de digestibilidade aparente da proteína bruta (CDPB) do capim-elefante no presente experimento foi de $24,60 \%$, inferior ao valor médio, de 36,58\%, obtido na literatura (ARAÚJO et al., 1996; FERREIRA et al., 1995; FURTADO et al., 1995; PEREIRA e QUEIROZ, 1997; e OLIVEIRA et al., 1997), enquanto o coeficiente de digestibilidade aparente da energia (CDE) foi de $41,60 \%$, superior aos reportados por ARAÚJO et al. (1996) e FURTADO et al. (1995), de 30,00 e 33,50\%, respectivamente.

O coeficiente de digestibilidade aparente da FDN (CDFDN) do capim-elefante no presente experimento foi de $40,60 \%$, valor próximo ao reportado por PEREIRA e QUEIROZ (1997), de 46,11\%, e superior ao valor médio de $33,80 \%$ obtido na literatura (ARAÚJO et al., 1996; FERREIRA et al., 1995; FURTADO et al., 1995; PEREIRA e QUEIROZ, 1997; e OLIVEIRA et al., 1997). O coeficiente de digestibilidade aparente da FDA (CDFDA) foi de $38,30 \%$, superior aos resultados obtidos por FERREIRA et al. (1995), OLIVEIRA et al. (1997), PEREIRA e QUEIROZ (1997), de 25,01; 23,80; e $31,50 \%$, respectivamente.

O coeficiente de digestibilidade aparente da celulose (CDCEL) do capim-elefante foi $45,60 \%$, superior aos resultados obtidos por FERREIRA et al. (1995), OLIVEIRA et al. (1997) e PEREIRA e QUEIROZ (1997), de 33,01; 29,80; e 30,79\%, respectivamente. No entanto, o coeficiente de digestibilidade aparente da hemicelulose (CDHEM) foi de 52,20\%, inferior ao resultado obtido por PEREIRA e QUEIROZ (1997), de 63,79\%, e superior ao obtido por FERREIRA et al. (1995), 39,70\%. Estes resultados demostram que os coeficientes de digestibilidade aparente dos componentes fibrosos do capim-elefante variam de 40 a $50 \%$.

O coeficiente de digestibilidade aparente da matéria seca (CDMS) do feno de alfafa no presente experimento foi de $55,20 \%$, inferior ao valor médio de $62,55 \%$ obtido na literatura (TOSI et al., 1982; LIEB et al., 1993; CUDDEFORD et al., 1995; TODD et al., 1995; ARAÚJO et al., 1996; e CROZIER et al., 1997).

O coeficiente de digestibilidade aparente da proteína bruta (CDPB) do feno de alfafa no presente experimento foi de $71,20 \%$, superior ao obtido por CUDDEFORD et al. (1992), de 36,00\%, e inferior ao valor médio de $77,88 \%$ observado na literatura (TOSI et al., 1982; LIEB et al., 1993; CUDDEFORD et al., 
Tabela 3 - Coeficientes médios de digestibilidade aparente de matéria seca (MS), matéria orgânica (MO), energia bruta $(E B)$, proteína bruta $(P B)$, extrato etéreo (EE), fibra bruta $(F B)$, fibra em detergente neutro (FDN), fibra em detergente ácido (FDA), celulose (CEL), hemicelulose (HEM) e lignina (LIG) do capim-elefante, feno de alfafa e feno de capim coast-cross

Table 3 - Mean coefficients of apparent digestibility of dry matter (DM), organic matter (OM), gross energy (GE), crude protein $(C P)$, ether extract (EE), crude fiber (CB), neutral detergent fiber (NDF), acid detergent fiber (ADF), cellulose (CEL), hemicellulose (HEM) and lignin (LIG) for elephant grass, alfalfa and coast-cross grass hay

\begin{tabular}{|c|c|c|c|c|}
\hline $\begin{array}{l}\text { Nutriente } \\
\text { Nutrient }\end{array}$ & $\begin{array}{l}\text { Capim-elefante } \\
\text { Elefant grass }\end{array}$ & $\begin{array}{c}\text { Feno de alfafa } \\
\text { Alfafa hay }\end{array}$ & $\begin{array}{c}\text { Feno de capim coast-cross } \\
\text { Coast-cross grass hay }\end{array}$ & $\mathrm{CV}$ \\
\hline \multicolumn{5}{|c|}{ Coeficiente de digestibilidade aparente $(\%)$} \\
\hline \multicolumn{5}{|c|}{ Coefficient of apparent digestibility } \\
\hline $\operatorname{MS}(D M)$ & $43,10^{\mathrm{b}}$ & $55,20^{\mathrm{a}}$ & $49,80^{\mathrm{ab}}$ & 10,8 \\
\hline $\mathrm{MO}(O M)$ & $44,50^{\mathrm{b}}$ & $56,90^{\mathrm{a}}$ & $50,50^{\mathrm{ab}}$ & 10,8 \\
\hline $\mathrm{EB}(G E)$ & $41,60^{\mathrm{b}}$ & $53,40^{\mathrm{a}}$ & $47,90^{\mathrm{ab}}$ & 11,8 \\
\hline $\mathrm{PB}(C P)$ & $24,60^{\mathrm{c}}$ & $71,20^{\mathrm{a}}$ & $56,10^{\mathrm{b}}$ & 9,0 \\
\hline $\mathrm{EE}$ & $34,40^{\mathrm{ab}}$ & $34,30^{\mathrm{ab}}$ & $58,50^{\mathrm{a}}$ & 34,9 \\
\hline $\mathrm{FB}(C B)$ & $48,50^{\mathrm{a}}$ & $34,40^{\mathrm{b}}$ & $47,30^{\mathrm{a}}$ & 16,7 \\
\hline $\mathrm{FDN}(N D F)$ & $40,60^{\mathrm{b}}$ & $35,50^{\mathrm{b}}$ & $63,30^{\mathrm{a}}$ & 7,9 \\
\hline $\mathrm{FDA}(A D F)$ & $38,30^{\mathrm{ab}}$ & $32,90^{\mathrm{b}}$ & $44,60^{\mathrm{a}}$ & 16,5 \\
\hline CEL (CEL) & $45,60^{\mathrm{a}}$ & $53,60^{\mathrm{a}}$ & $54,30^{\mathrm{a}}$ & 11,8 \\
\hline $\operatorname{HEM}(H E M)$ & $52,20^{\mathrm{b}}$ & $40,20^{\mathrm{c}}$ & $83,50^{\mathrm{a}}$ & 11,8 \\
\hline $\operatorname{LIG}(L I G)$ & $-6,30^{b}$ & $40,90^{\mathrm{a}}$ & $-8,40^{b}$ & 244,4 \\
\hline
\end{tabular}

Médias, na linha, seguidas de letras diferentes são diferentes pelo teste Newman-Kews $(P>0,05)$.

Means, within a row, followed by different letters are different by Newman-Kews test $(P>05)$.

1995; TODD et al., 1995; ARAÚJO et al., 1996; e CROZIER et al., 1997). O coeficiente de digestibilidade aparente da energia (CDE) foi de $53,40 \%$, superior aos reportados por CUDDEFORD et al. (1992) e TODD et al. (1995), de 43,00 e 44,70\%, respectivamente, e inferior aos resultados reportados por ARAÚJO et al. (1996), CUDDEFORD et al. (1995) e LIEB et al. (1993), de 64,49; 64,00; e $61,00 \%$, respectivamente.

O coeficiente de digestibilidade aparente da FDN (CDFDN) do feno de alfafa no presente experimento foi de $35,50 \%$, valor próximo a $35,70 \%$ reportado por FONNESBECK (1968) e inferior ao valor médio de $43,90 \%$ observado na literatura (CUDDEFORD et al., 1992; LIEB et al., 1993; CUDDEFORD et al., 1995; TODD et al., 1995; ARAÚJO et al., 1996; e CROZIER et al., 1997). O coeficiente de digestibilidade aparente da FDA (CDFDA) foi de $32,90 \%$, próximo ao valor médio de $35,02 \%$ observado na literatura (FONNESBECK, 1968; TOSI et al., 1982; CUDDEFORD et al., 1992; LIEB et al., 1993; CUDDEFORD et al., 1995; e CROZIER et al., 1997). Entretanto, o coeficiente de digestibilidade aparente da celulose (CDCEL) e da hemicelulose (CDHEM) foi de 53,60 e 44,70\%, respectivamente, resultados superiores aos valores médios de 42,21 e $36,85 \%$, respectivamente, observados na literatura (FONNESBECK, 1968; LIEB et al., 1993; e CROZIER et al., 1997).
O coeficiente de digestibilidade aparente da matéria seca (CDMS) do feno de capim coast-cross no presente experimento foi de $49,80 \%$, superior aos reportados por AIKEN et al. (1989) e LIEB et al. (1993), de 43,00 e 41,00\%, respectivamente, e semelhante aos resultados reportados por TOSI et al. (1982), DUGAN et al. (1993) e ARAÚJO et al. (1996), os quais variaram de 46,86 a 49,98\%.

O coeficiente de digestibilidade aparente da proteína bruta (CDPB) do feno de capim coast-cross no presente experimento foi de $56,10 \%$, superior aos resultados reportados por TOSI et al. (1982), de $40,15 \%$, e AIKEN et al. (1989), de 50,70\%, no entanto, foi inferior ao valor médio de $68,10 \%$ observado na literatura (LIEB et al., 1993; DUGAN et al., 1993; e ARAÚJO et al., 1996). O coeficiente de digestibilidade aparente da energia (CDE) foi de $47,90 \%$, superior aos reportados por AIKEN et al. (1989), LIEB et al. (1993) e ARAÚJO et al. (1996), de 42,10; 42,00; e 45,33\%, respectivamente.

Os coeficientes de digestibilidade aparente da fibra em detergente neutro (CDFDN), fibra em detergente ácido (CDFDA), celulose (CDCEL) e hemicelulose (CDHEM) do feno de coast-cross, no presente experimento, foram de 63,30; 44,60; 54,30; e $83,50 \%$, respectivamente, superiores aos valores médios de $42,91 \%$ para o CDFDN; $36,46 \%$ para o CDFDA; $41,96 \%$ para o CDCEL; e $53,53 \%$ para o CDHEM, reportados na literatura (FONNESBECK, 
1968; TOSI et al., 1982; AIKEN et al., 1989; LIEB et al., 1993; DUGAN et al., 1993; e ARAÚJO et al., 1996).

O feno de alfafa apresentou valores médios dos CDMS, CDMO e CDE próximos a 55,0\%, significativamente maiores $(\mathrm{P}<0,05)$ que os valores médios do capim-elefante, próximos de $43,0 \%$, enquanto os valores intermediários, próximos de $50,0 \%$, foram observados para o feno de coast-cross. Estas diferenças podem estar relacionadas com os maiores teores de FDN e FDA, que foram observados no capim-elefante e no feno de coast-cross. O valor do CDPB do feno de alfafa apresentou-se maior $(\mathrm{P}<0,05)$ que o valores observados para as gramíneas, enquanto o valor do CDPB do feno de coast-cross apresentou-se maior $(\mathrm{P}<0,05)$ que o valor observado para o capim-elefante.

Os valores do CDFDN e CDHEM do feno de coast-cross foram maiores $(\mathrm{P}<0,05)$ que os valores observados para o capim-elefante e feno de alfafa, enquanto o valor do CDFDA foi maior $(\mathrm{P}<0,05)$ que o obtido para o feno de alfafa. Os valores do CDCEL dos alimentos volumosos capim-elefante, feno de alfafa e feno de coast-cross foram similares.

Os percentuais médios de matéria seca digestível (MSD), matéria orgânica digestível (MOD), proteína digestível (PD), energia digestível (ED), fibra em detergente neutro digestível (FDND), fibra em detergente ácido digestível (FDAD), celulose digestível (CELD) e hemicelulose digestível (HEMD) dos alimentos avaliados encontram-se na Tabela 4.

O valor observado para ED do capim-elefante foi de $1,78 \mathrm{Mcal} / \mathrm{kg} \mathrm{MS}$, superior ao obtido por FERREIRA (1994), de 1,17 Mcal/kg MS, e próximo aos valores obtidos por MACHADO (1992) e FURTADO et al. (1995), de 1,78 e 1,50 Mcal/kg MS, respectivamente. A ED observada para o feno de capim coast-cross foi de 2,08 Mcal/kg MS, superior ao valor médio de $1,94 \mathrm{Mcal} / \mathrm{kg}$ MS obtido na literatura (FONNESBECK et al., 1967; FONNESBECK, 1968; GIBBS et al., 1988; AIKEN et al., 1989; e BOMBARDA, 1989). Entretanto, o valor de ED do feno de alfafa foi de 2,33 Mcal/ $\mathrm{kg}$ MS, semelhante ao valor médio de $2,32 \mathrm{Mcal} / \mathrm{kg}$ MS observado por ALMEIDA et al. (1998), revisando a literatura corrente sobre o uso da alfafa na alimentação de eqüinos.

Os consumos médios diários de matéria seca digestível (MSD), matéria orgânica digestível(MOD), proteína digestível (PD), energia digestível (ED), fibra em detergente neutro digestível (FDND), fibra em detergente ácido digestível (FDAD), celulose digestível (CELD) e hemicelulose digestível (HEMD) dos alimentos avaliados encontram-se na Tabela 5 .

O consumo voluntário de energia digestível (ED) dos animais alimentados com capim-elefante e feno de capim coast-cross foi de 11,04 e 12,1 Mcal, cerca de 82 e $87 \%$, respectivamente, dos requerimentos diários recomendados pelo NRC (1989), enquanto o consumo de ED nos animais alimentados com feno de alfafa foi $16,33 \mathrm{Mcal}$, cerca de $116 \%$ do requerimento diário recomendado pelo NRC (1989).

O consumo voluntário de proteína bruta $(\mathrm{PB})$, expresso em g de PB/Mcal ED, foi de 19,9; 83,9; e $29,9 \mathrm{~g}$, para os animais alimentados com capimelefante, feno de alfafa e feno de capim coast-cross, que, ao ser comparado com o consumo diário de $\mathrm{PB}$ recomendado pelo NRC (1989), de $40 \mathrm{~g}$ de PB/Mcal $\mathrm{ED}$, indica que apenas os animais alimentados com feno de alfafa consumiram quantidades de PB suficientes para a mantença. Em relação ao consumo de proteína digestível (PD), o NRC (1989) recomenda que o consumo médio diário seja de $0,60 \mathrm{~g} \mathrm{PD} / \mathrm{kg}$ PV; portanto, no presente experimento os animais alimentados com capim-elefante e feno de capim coast-cross consumiram diariamente 54,0 e $204 \mathrm{~g}$ de PD, cerca de 22,38 e 77,80\% da recomendação diária. $\mathrm{O}$ consumo diário de $\mathrm{PD}$ nos animais alimentados com feno de alfafa foi de $974 \mathrm{~g}$ PD, cerca de 385,6\% da exigência diária, bastante superior ao recomendado pelo NRC (1989).

Avaliando-se os alimentos em conjunto, de acordo com os requerimentos em ED e PD para mantença propostos pelo NRC (1989), verifica-se que o capimelefante supriu cerca de $82 \%$ da ED e apenas $22 \%$ da $\mathrm{PD}$, demonstrando ser um alimento bastante deficiente em PD para eqüinos. $O$ feno de capim coastcross supriu cerca de $87 \%$ da ED e $78 \%$ da PD, mostrando ser um alimento equilibrado em energia e proteína para eqüinos, sendo necessária a complementação destes nutrientes por outros alimentos volumosos ou concentrados, em dietas para eqüinos adultos em mantença.

O feno de alfafa supriu cerca $116 \%$ da ED e $385 \%$ da PD, mostrando-se adequado do ponto de vista energético. Entretanto, a quantidade de proteína digerida no trato digestivo excedeu em muito as exigências para eqüinos adultos em mantença, devendo ser considerado que o excesso de nitrogênio absorvido pelo trato digestivo será excretado na urina. Nas áreas urbanas, em hípicas e jockey clubes, é comum a manutenção de eqüinos retidos em baias, onde a conversão dos compostos nitrogenados, excretados nas fezes e urina, em amônia pelos microrganismos, causa problema adicional à poluição 
ALMEIDA et al.

Tabela 4 - Valores médios de matéria seca digestível (MSD), matéria orgânica digestível (MOD), proteína digestível (PD), energia digestível (ED), fibra em detergente neutro digestível (FDND), fibra em detergente ácido digestível (FDAD), celulose (CELD) e hemicelulose digestíveis (HEMD), com base na matéria seca, do capim-elefante, feno de alfafa e feno de capim coast-cross.

Table 4 - $\quad$ Mean values of digestible dry matter (DDM), digestible organic matter (DOM), digestible protein (DP), digestible energy (DE), digestible neutral detergent fiber (DNDF), digestible acid detergent fiber (DADF), digestible cellulose (DCEL) and digestible hemicellulose (DHEM), in dry matter basis, for elephant grass, alfalfa and coast-cross grass hays

\begin{tabular}{lccc}
\hline Item & $\begin{array}{c}\text { Capim-elefante } \\
\text { Elefant grass }\end{array}$ & $\begin{array}{c}\text { Feno de alfafa } \\
\text { Alfafa hay }\end{array}$ & $\begin{array}{c}\text { Feno de capim coast-cross } \\
\text { Coast-cross grass hay }\end{array}$ \\
\hline MSD $(\%)(D D M)$ & 11,22 & 47,31 & 42,55 \\
MOD $(\%)(D O M)$ & 41,58 & 51,60 & 48,14 \\
PD $(\%)(D P)$ & 0,87 & 13,84 & 3,52 \\
ED $($ Mcal/kg MS) $(D E)$ & 1,78 & 2,33 & 2,08 \\
FDND $(\%)(D N D F)$ & 35,32 & 20,85 & 56,10 \\
FDAD $(\%)(D A D F)$ & 18,04 & 12,02 & 20,53 \\
CELD $(\%)(D C E L)$ & 18,58 & 14,43 & 21,20 \\
HEMD $(\%)(D H E M)$ & 20,86 & 8,90 & 35,49 \\
\hline
\end{tabular}

Tabela 5 - Consumo médio diário de matéria seca digestível (MSD), matéria orgânica digestível (MOD), proteína digestível (PD), energia digestível (ED), fibra em detergente neutro digestível (FDND), fibra em detergente ácido digestível (FDAD), celulose (CELD) e hemicelulose digestíveis (HEMD), do capim-elefante, feno de alfafa e feno de capim coast-cross

Table 5 - Mean daily intake of digestible matter dry (DDM), digestible organic matter (DOM), digestible protein (DP), digestible energy $(D E)$, digestible neutral detergent fiber (DNDF), digestible acid detergent fiber (DADF), digestible cellulose (DCEL) and digestible hemicelluloses (DHEM), in dry matter basis, for elephant grass, alfalfa and coast-cross grass hays

\begin{tabular}{|c|c|c|c|c|c|c|c|c|}
\hline $\begin{array}{l}\text { Dieta } \\
\text { Diet }\end{array}$ & $\begin{array}{c}\text { MSD } \\
(\mathrm{kg}) \\
D D M\end{array}$ & $\begin{array}{c}\text { MOD } \\
(\mathrm{kg}) \\
D O M\end{array}$ & $\begin{array}{c}\text { PD } \\
(\mathrm{kg}) \\
D P\end{array}$ & $\begin{array}{c}\mathrm{ED} \\
\text { (Mcal) } \\
D E\end{array}$ & $\begin{array}{c}\text { FDND } \\
(\mathrm{kg}) \\
D N D F\end{array}$ & $\begin{array}{c}\text { FDAD } \\
(\mathrm{kg}) \\
D A D F\end{array}$ & $\begin{array}{c}\text { CELD } \\
(\mathrm{kg}) \\
D C E L\end{array}$ & $\begin{array}{c}\text { HEMD } \\
(\mathrm{kg}) \\
D H E M\end{array}$ \\
\hline $\begin{array}{l}\text { Capim-elefante } \\
\text { Elefant grass }\end{array}$ & 2,678 & 2,583 & 0,054 & 11,036 & 2,210 & 1,118 & 1,154 & 1,298 \\
\hline $\begin{array}{l}\text { Feno de alfafa } \\
\text { Alfafa hay }\end{array}$ & 3,878 & 3,632 & 0,974 & 16,333 & 1,456 & 0,846 & 1,018 & 0,615 \\
\hline $\begin{array}{l}\text { Feno de capim coast-cross } \\
\text { Coast-cross grass hay }\end{array}$ & 2,888 & 2,793 & 0,204 & 12,051 & 3,256 & 1,195 & 1,234 & 2,057 \\
\hline
\end{tabular}

ambiental, que é o efeito deletério da amônia nas vias respiratórias dos animais (CHURCH, 1993). Portanto, a utilização deste alimento como dieta exclusiva para eqüinos adultos em mantença não é adequada.

\section{Conclusões}

O consumo de matéria seca do capim-elefante e dos fenos de alfafa e capim coast-cross foi semelhante, enquanto o coeficiente de digestibilidade aparente da $\mathrm{PB}$ do feno de alfafa foi superior ao do capim-elefante e do feno de capim coast-cross e o coeficiente de digestibilidade aparente da FDN do feno de capim coast-cross foi superior ao do capimelefante e do feno de alfafa, em função da maior digestibilidade da fração correspondente à hemicelulose no feno de capim coast-cross.

$\mathrm{O}$ feno de capim coast-cross apresentou-se como alimento equilibrado em energia e proteína digestíveis, com 2,08 Mcal ED/kg MS e 35,17 g PD/kg MS, respectivamente, sendo necessária a complementação destes nutrientes por outros alimentos volumosos ou concentrados, em dietas para eqüinos adultos em mantença. O capim-elefante apresentou-se deficiente em energia e proteína digestíveis, com 1,78 Mcal $\mathrm{ED} / \mathrm{kg} \mathrm{MS}$ e $8,68 \mathrm{~g} \mathrm{PD} / \mathrm{kg} \mathrm{MS}$, respectivamente. O feno de alfafa mostrou-se adequado do ponto de vista energético, com 2,33 Mcal ED/kg MS, porém a quantidade de proteína digestível, de 138,54 g PD/kg MS, excedeu as exigências de eqüinos adultos em mantença. 


\section{Referências Bibliográficas}

AIKEN, G.E., POTTER, G.D., CONRAD, B.E. et al. 1989. Voluntary intake and digestion of coastal bermuda grass hay by yearling and mature horses. J. Eq. Vet. Sci., 9(5): 262-264.

ALMEIDA, M.I.V., FERREIRA, W.M., ALMEIDA, F.Q. et al. 1999. Composição química e predição do valor nutritivo de dietas para eqüinos. Rev. bras. zootec. (no prelo).

ARAÚJO, K.V., LIMA, J.A.F., TEIXEIRA, J.C. et al. 1996. Determinação da digestibilidade aparente dos nutrientes de alguns concentrados de volumosos para eqüinos, pela técnica dos saco de náilon móvel. R. Soc. Bras. Zootec., 25(5):944-956.

ARCHER, M. 1973. The species preferences of grazing horses. J. Brit. Grassl. Soc., 28:123-128.

BOMBARDA, A.F. Efeito da forma física do concentrado sobre a digestibilidade de nutrientes em rações de eqüinos. Piracicaba, SP, 1989. 53p. Dissertação (Mestrado em Nutrição Animal e Pastagens). Escola Superior de Agricultura "Luiz de Queiroz - Universidade de São Paulo, 1989.

CHURCH, N.W. Poor air hygiene: what cost to equine performance. In: BIOTECHNOLOGY IN THE FEED INDUSTRY, 9, Nicholasville, 1993. Proceedings... Nicholasville. ALTECH, 1993, p.343-354.

CROZIER, J.A., ALLEN, V.G., JACK, N.E. et al. 1997. Digestibility, apparent mineral absorption, and voluntary intake by horses fed alfafa, tall fescue, and caucasian bluestem. J. Anim. Sci., 75:1651-1658.

CUDDEFORD, D., PEARSON, R.A., ARCHIBALD, R.F. et al. 1995. Digestibility and gastro-intestinal transit time of diets containing different proportions of alfafa and oat straw in througbreds, Shetland ponies, Higland ponies and donkeys. J. Anim. Sci., 61:407-417.

CUDDEFORD, D., WOODHEAD, A., MUIRHEAD, R. 1992. A comparison between the nutritive value of short-cutting cycle, high temperature-dried alfafa and tymothy hay for horses. Eq. Vet. J., 24(2):84-89.

CYMBALUK, N.F. 1989. Effects of dietary energy source and level of feed intake on growth of weanling horses. Eq. Practice, 11(9):29-33.

DUGAN, K.G., POND, K.R., BURNS, J.C. et al. A comparison of intake and digestibility of coastal bermudagrass and flaccidrass hays in horses. In: EQUINE NUTRITION AND PHYSIOLOGY SIMPOSIUM, 13, Gainesville, 1993. Proccedings....Gainesville: Equine Nutrition and Physiology Society, 1993, p.11-15.

DULPHY, J.P., JOUANY, J.P., MARTIN-ROSSET, W. et al. 1994. Aptitudes comparées de différentes espèces d'herbivores domestiques à ingérer et digérer des fourrages distribués à l'auge. Ann. Zootech., 43:11-32.

DULPHY, J.P., MARTIN-ROSSET, W., DUBROEUCQ, H. et al. 1997. Evaluation of voluntary intake of forage trough-fed to light horses. Comparasion with sheep. Factors of variation and prediction. Liv. Prod. Sci., 52:97-104.

FERREIRA, S.C. Consumo e digestibilidade de dietas mistas compostas por capim elefante (Pennisetum purpureum) $e$ feno de guandu (Cajanus cajan) em eqüinos. Belo Horizonte, MG, Escola de Veterinária da UFMG. 1994, 69p. Dissertação (Mestrado em Zootecnia)-Universidade Federal de Minas Gerais, 1994.

FERREIRA, S.C., GONÇALVES, L.C., REZENDE, A.S.C. et al. 1995. Avaliação do consumo e da digestibilidade do capim elefante (Pennisetum purpureum) picado e do feno de guandu (Cajanus cajan) desintegrado em eqüinos. Arq. Bras. Med. Vet. Zootec., 47(2):239-248.
FONNESBECK, P.V. 1968. Digestion of soluble and fibrous carbohydrate of forage by horses. J. Anim. Sci., 27(5):13361344.

FONNESBECK, P.V., LYDMAN, R.K., VANDERNOOT, G.W. et al. 1967. Digestibility of the proximate nutrients of forages by horses. J. Anim. Sci., 26(5):1039-1045.

FURTADO, S.I, CARDOSO, R.M., COELHO DA SILVA, J.F. et al. 1995. Efeito de níveis de uréia na digestibilidade de rações para eqüinos. R. Soc. Bras. Zootec., 24(4):623-631.

GIBBS, P.G., POTTER, G.D., SCHELLING, G.T. et al. 1988. Digestion of the hay protein in different segments of the equine digestive tract. J. Anim. Sci., 66:400-406.

HINTZ, H.F. 1988. Effect of level of intake on digestibility. Eq. Practice, 10(3):5-6.

HOUPT, K.A. 1990. Ingestive behavior The Veterinary Clinics of North America. Equine Practice, 6(2):319-337.

LIEB, OTT, E.A., FRENCH, E.C. Digestible nutrients and voluntary intake of rhizomal peanut, alfafa, bermudagrass and bahiagrass hays by equine. In: EQUINE NUTRITION AND PHYSIOLOGY SIMPOSIUM, 13, Gainesville, 1993. Proccedings....Gainesville. Equine Nutrition and Physiology Society, 1993, p. 98-99.

MACHADO, H.M. Efeito de diferentes combinações de capim elefante (Penninsetum purpureum, Schum): cana-de-açúcar (Saccharum officinarum, L.) sobre a digestibilidade, em eqüinos, utilizando diferentes metodologias de determinação. Viçosa, MG : UFV, 1992. 71p. Dissertação (Mestrado em Zootecnia) - Universidade Federal de Viçosa, 1992.

MARTIN-ROSSET, W., DULPHY, J.P. 1987. Digestibility interactions between forages and concentrates in horses: influence of feeding level - comparison with sheep. Livestock Prod. Sci., 17:263-276.

MERTENS, D.R. Análise da fibra e sua utilização na avaliação de alimentos e formulação de rações: In: REUNIÃO ANUAL DA SOCIEDADE BRASILEIRA DE ZOOTECNIA, 29, 1992, Lavras. Anais... Lavras: SBZ, 1992, p.188-219.

MEYER, H. 1995. Alimentação de cavalos. São Paulo: Ed. Varela. 303p.

MINSON, D.J. 1990. Forage in ruminant nutrition. New York: Academic Press. 483p.

NATIONAL RESEARCH COUNCIL - NRC. 1989. Nutrient Requirements of Horses. 5 ed. Washington. National Academy of Science. 100p.

OLIVEIRA, A.A.M.A. Digestão total e pré-cecal dos nutrientes em potros fistulados no íleo. Viçosa, MG: UFV, 92p. 1995. Dissertação (Mestrado em Zootecnia) - Universidade Federal de Viçosa, 1995.

OLIVEIRA, A.A.M.A., QUEIROZ, A.C., VALADARES FILHO, S.C. et al. 1998. Digestão total e pré-cecal dos nutrientes em potros fistulados no íleo. R. Bras. Zootec., 27(2):331-337.

PAGAN, J.D. Forages for horses. In: BAIN-FALLON MEMORIAL LECTURES. EQUINE NEUROLOGY AND NUTRITION, 18, 1996, Glenelg. Proceedings...Glenelg. Australian Equine Veterinary Association, 1996, p.189-205.

PEREIRA, J.C., QUEIROZ, A.C. 1997. Digestibilidade aparente em eqüinos alimentados com capim elefante (Pennisetum purpureum, Schum) e cana-de-açucar (Saccharum officinarum, L.) em diversas combinações. R. Bras. Zootec., 26(1):105-110.

RALSTON, S.L. 1984. Controls of feeding in horses. J. Anim. Sci., 59:1354-1361.

REIS, R.A., RODRIGUES, L.R.A. 1993. Valor nutritivo de plantas forrageiras. Jaboticabal - FCAVJ - UNESP-FUNEP. 26p.

SILVA, D.J. 1990. Análise de alimentos: métodos químicos e 
biológicos. 2 ed. Viçosa: UFV/Imprensa Universitária. 165p. SMOLDERS, E.A.A., STEG, A., HINDLE, V.A. 1990. Organic matter digestibility in horses and its prediciton. Netherlands J. Agric. Sci., 38:435-447.

TODD, K.L., SAUER, W.C., CHRISTOPHERSON, R.J. et al. 1995. The effect of feeding different forms of alfafa on nutrient digestibility and voluntary intake in horses. J. Anim. Phisiol. Anim. Nut., 73:1-8.

TOSI, H., FAVORETTO, V., JESUS, W.R. et al. Valor nutritivo de fenos de gramíneas e de leguminosas forrageiras através de ensaio de digestibilidade com eqüinos. In: REUNIÃO ANUAL DA SOCIEDADE BRASILEIRA DE ZOOTECNIA, 19, Piracicaba, 1982. Anais...Piracicaba. SBZ, 1982, p. 260-262.

UNIVERSIDADE FEDERAL DE VIÇOSA - UFV. Sistema de análises estatísticas e genéticas - SAEG. Viçosa: Universidade Federal de Viçosa, 1997. Manual do usuário, 150p. (versão 7.0).

VAN ES, A.J.H., VAN DER MEER, J.M. 1980. Methods of analysis for predicting the energy and protein value offeeds for farm animals. Van der Meer. p.46-55.
VAN SOEST, P.J. 1967. Development of a comprehensive system of feed analyses and its application to forages. $J$. Anim. Sci., 26(1):119-128.

VAN SOEST, P.J. 1994. Nutritional ecology of the ruminant. 2. ed. Ithaca, Cornell University Press, 476p.

VAN SOEST, P.J., ROBERTSON, J.B., LEWIS, B.A. 1991. Methods for dietary fiber, neutral detergent fiber, and nonstarch polysaccharides in relation to animal nutrition. $J$. Dairy Sci., 74:3583-3597.
Recebido em: 02/07/98

Aceito em: 22/12/98 